\title{
Diferentes encaminhamentos para um mesmo tema em atividades de modelagem matemática
}

Elida Maiara Velozo de Castro elidamaiara.vc@.gmail.com

https://orcid.org/0000-0002-2310-1774 Universidade Estadual do Paraná (UNESPAR), União da Vitória, Paraná, Brasil

Michele Regiane Dias Veronez miredias@gmail.com

https://orcid.org/0000-0001-9464-1498 Universidade Estadual do Paraná (UNESPAR) Apucarana, Paraná, Brasil

\section{RESUMO}

Pesquisas sobre modelagem matemática na educação matemática têm apresentado contribuições relevantes para o ensino, bem como têm provocado reflexões acerca da utilização do recurso como meio didático voltado para a compreensão de situações do cotidiano ou do interesse dos alunos. O presente estudo tem como objetivo discutir como diferentes atividades de modelagem matemática podem surgir de um mesmo tema de interesse. Assim, apresentamos os encaminhamentos adotados por dois grupos de alunos, do 8 ano do Ensino Fundamental, destacando a dinâmica proporcionada por atividades de modelagem matemática no contexto das aulas de matemática. Este trabalho segue orientações da abordagem qualitativa, uma vez que utiliza dados que requerem interpretação: observações em sala de aula, transcrições das gravações em áudio, registros escritos e demais produções dos alunos. Os resultados apontam que uma mesma temática, estudada por grupos distintos, embora possa apresentar alguns aspectos tratados de maneira semelhantes, se diferencia em vários outros aspectos. Em ambiente de modelagem matemática a aplicação do tema comum varia, por exemplo, nos conceitos matemáticos utilizados no desenvolvimento de cada atividade, trazendo à tona diferentes conhecimentos matemáticos e não matemáticos dos alunos.

PALAVRAS-CHAVE: Atividades de modelagem matemática. Fases da Modelagem Matemática. Encaminhamentos. 


\section{INTRODUÇÃO}

A crítica ao modelo de ensino tradicional e conteudista nos remete a pensar na necessidade de metodologias, alternativas e práticas pedagógicas capazes de incentivar o aluno a desenvolver capacidades de criar, de construir e de aprender conceitos que permitam a leitura e compreensão do mundo real.

A ideia de formação de indivíduos aptos a aprender por meio de atividades que envolvam fenômenos de seu cotidiano, da sua realidade, buscando explicá-los matematicamente, agindo e decidindo em determinadas circunstâncias, pode ser proporcionada pela Modelagem Matemática.

Embora existam diversas concepções e abordagens que tratam da Modelagem Matemática na Educação Matemática, Tortola, Rezende e Santos (2010) destacam que elas possuem ideias comuns; como o fato de que sinalizam o uso de situações cotidianas para o ensino e aprendizagem da Matemática. O desenvolvimento de atividades de modelagem matemática em sala de aula possibilita trabalhar diversas potencialidades e conhecimentos dos alunos ao mesmo tempo em que é favorecido explorar situações que os levem a mobilizar seus conhecimentos e complementá-los à medida que se envolvem com o tema que originou a atividade de modelagem e buscam uma resposta para o problema identificado a partir do tema em estudo.

Dessa forma, o tema de investigação que orienta a atividade de modelagem matemática pode gerar inúmeras possibilidades de estudo e atender a diferentes propósitos pedagógicos. Nesse trabalho olhamos para os diferentes modos que dois grupos de alunos trataram um tema que originou, portanto, duas atividades de modelagem. Esse fato nos remete a considerar e refletir sobre o modo como um mesmo tema pode conduzir os alunos a diferentes problemas, encaminhamentos e estratégias, elucidando o caráter "aberto" e flexível de atividades de modelagem matemática. Este artigo é derivado de um trabalho apresentado no XIV Encontro Paranaense de Educação Matemática (EPREM).

Assim, temos por objetivo discutir acerca dos encaminhamentos assumidos por dois grupos de alunos de um $8^{-}$ano ao desenvolverem atividades de modelagem matemática a partir de um mesmo tema. Para tanto, abordamos as fases da Modelagem Matemática, apresentamos os aspectos metodológicos do estudo, elucidamos a análise realizada com base nos encaminhamentos assumidos pelos alunos em cada fase da atividade e, por fim, tecemos algumas considerações sobre o estudo realizado.

\section{A MODELAGEM MATEMÁTICA E SUAS FASES}

De modo geral, uma atividade de modelagem matemática, segundo Veronez e Veleda (2016, p.1238) "parte de um problema da realidade, sendo que na busca por soluções para esse problema utiliza-se conhecimentos matemáticos". A Modelagem Matemática consiste, portanto, em partir de uma situação inicial, também conhecida como problemática, e chegar a uma situação final, que corresponde à solução para a problemática, que vem associada a uma representação ou modelo matemático' (ALMEIDA; SILVA; VERTUAN, 2013). 
Nesta transição da situação inicial para a final há mobilização de um conjunto de procedimentos. Tais procedimentos compreendem o entendimento da situação por parte dos alunos e são manifestados por eles na organização das informações, no levantamento de hipóteses, nos conceitos matemáticos, ou seja, nos encaminhamentos que assumem enquanto investigam o problema que se propuseram estudar.

$\mathrm{Na}$ intenção de amparar, orientar e, de certo modo, organizar o desenvolvimento de atividades de modelagem matemática, Almeida, Silva e Vertuan (2013) sugerem algumas fases para a Modelagem Matemática: inteiração, matematização, resolução, interpretação de resultados e validação. Entretanto, segundo os autores, como atividades dessa natureza têm caráter aberto e flexível, a ordem em que essas fases aparecem pode variar, bem como o tempo destinado a cada uma delas, de acordo com a dinâmica que demanda cada situação e com o movimento de "ida e vinda" entre as fases ${ }^{2}$.

A fase inteiração refere-se ao primeiro contato com a situação-problema, definida como o ato de inteirar-se. Significa que nessa fase é momento de informar-se, tornar-se ciente, tomar conhecimento a respeito da situação. Essa fase da atividade de modelagem matemática acontece a partir da escolha do tema e tem como foco a busca por informações, com vistas a conhecer características da situação em estudo. Nesta fase é o momento de tornar alguns aspectos conhecidos e conduzir a formulação ou identificação do problema matemático, ao mesmo tempo em que se definem metas para a sua resolução.

Se o momento é de tornar o tema conhecido, faz-se necessário consultar fontes como livros, sites, revistas, entrevistas com pessoas especialistas no assunto e pesquisa de campo, que embasem e auxiliem a compreensão da situação. Conhecer aspectos da situação em foco sugere pesquisar, registrar e discutir informações e coletar dados - qualitativos e/ou quantitativos - sobre o tema, que sirvam de respaldo para desenvolver a atividade de modelagem matemática.

Como ao longo do desenvolvimento da atividade de modelagem matemática pode surgir a necessidade de novas informações relativas ao contexto do tema escolhido, a inteiração, embora seja uma fase inicial, pode estender-se durante todo o desenvolvimento da atividade.

A situação-problema identificada na fase inteiração geralmente se apresenta em linguagem natural, isso evidencia a necessidade da transição da linguagem natural para a linguagem matemática, momento que Almeida, Silva e Vertuan (2013, p.16), denominam matematização e definem como

\begin{abstract}
a busca e elaboração de uma representação matemática são mediadas por relações entre as características da situação e os conceitos, técnicas e procedimentos matemáticos adequados para representar matematicamente essas características. Daí que a segunda fase da Modelagem Matemática é caracterizada por "matematização", considerando esses processos de transição de linguagens, de visualização e de uso de símbolos para realizar descrições matemáticas.
\end{abstract}

Essa fase, matematização, prioriza a descrição matemática do problema, requer a seleção de variáveis, o levantamento de hipóteses e o encaminhamento da elaboração do modelo matemático, levando em consideração aspectos da situação inicial, entendidos como relevantes para o problema investigado 
(VERTUAN, 2013). A descrição matemática da situação, nesse sentido, possibilita atribuir significado matemático à organização da realidade, ou seja, a matematização pode ser descrita como uma tradução de linguagens que permite retratar a realidade por meio de regras, métodos e teorias matemáticas. A fase matematização, de modo geral, evidencia técnicas e procedimentos matemáticos a serem utilizados na fase de resolução.

A resolução é a fase que consiste na elaboração de um modelo matemático com o objetivo de descrever e analisar aspectos relevantes da situação, responder às questões e à problemática admitida na situação inicial, sendo possível, em alguns casos, realizar previsões para o problema em foco.

Nessa fase o sujeito utiliza conceitos, técnicas, métodos e representações matemáticas, põe em uso seus conhecimentos prévios, busca padrões, recorre a ferramentas computacionais, coordena diferentes representações dos objetos matemáticos, busca conhecer conceitos novos e ressignifica os já conhecidos [...] (VERTUAN, 2013, p.35).

Nessa compreensão o modelo matemático, construído nessa fase, é reconhecido como uma estrutura matemática que representa alguma coisa cuja finalidade pode ser "prever o comportamento de um fenômeno, ser demonstrativo de algo (como uma maquete), ter um fim pedagógico (auxiliar na ilustração de um conceito), ser descritivo de algo, entre outras coisas" (ALMEIDA; SILVA; VERTUAN, 2013, p.13). Ao utilizar-se de um conjunto de símbolos e relações matemáticas, que retratam de alguma forma a situação em estudo e direcionam para uma solução para o problema advindo dessa situação é que o modelo matemático pode ser evidenciado. Além de expor e explicar características matemáticas da situação, o modelo matemático carrega características dela.

A obtenção do modelo, dessa forma, é sempre uma aproximação conveniente da realidade analisada, mas que, segundo Bassanezi (1999), não garante a resolução do problema, nem conclui uma verdade definitiva. Assim, se um modelo não atinge a determinados objetivos ou é inadequado para representar a situação em estudo, é natural a busca por novos caminhos que permitam construir outro melhor ou analisá-lo admitindo como referência um modelo já conhecido.

Nesse sentido Veronez (2013), descreve que

\begin{abstract}
a elaboração de modelos matemáticos não tem um fim em si mesma; visa incentivar a busca por uma solução para o problema evidenciado na situação inicial, alicerçada por atitudes interpretativas. Essa busca também conduz a uma leitura da situação ou à retomada de alguns aspectos não considerados em momento anterior. Além disso, no contexto de sala de aula, favorece discussões sobre conceitos, notações e/ou procedimentos matemáticos (p.24).
\end{abstract}

A autora deixa claro que a elaboração do modelo não garante a solução do problema, mas que dela decorre a necessidade de interpretar as respostas e verificar se esta satisfaz a situação inicial. Caso contrário, é necessário retomar a situação e adotar outros possíveis encaminhamentos para a resolução do mesmo problema.

Analisar a solução no contexto da situação inicial constitui um processo Página | 474 avaliativo realizado pelos envolvidos com a atividade. Segundo Almeida, Silva e Vertuan (2013), a fase caracterizada como interpretação de resultados e validação, 
leva em consideração os procedimentos matemáticos e a resposta obtida no sentido de analisar se ela é adequada. É também nessa fase que se avalia o processo de construção de modelos e se valida o(s) resultado(s) para o problema, para, posteriormente, avaliar a resposta quanto a sua validade e importância.

Vertuan (2013, p.36), afirma que caso os alunos que lidam com a situação entendam que a resposta é adequada, eles devem comunicar "a resposta do problema para os outros alunos de modo a argumentar e convencer o outro de que a solução apresentada é razoável e consistente, tanto do ponto de vista matemático quanto do ponto de vista da situação inicial". Ainda segundo o autor, se a resposta obtida não for aceitável é necessário buscar novas informações, reestruturar as hipóteses e reiniciar o processo, sendo pertinente retornar à situação inicial e rever escolhas e procedimentos.

De modo geral, as fases relativas a uma atividade de modelagem matemática, segundo Almeida, Silva e Vertuan (2013), evidenciam alguns aspectos relevantes em atividades dessa natureza que podem ser descritos como: a situação-problema que dá início à atividade; os procedimentos de resolução e as soluções, ainda alheios ao conhecimento dos envolvidos; o processo de investigação de um problema; os conceitos matemáticos utilizados e; a análise interpretativa da solução. No Quadro 1 destacamos as principais características de cada uma das fases que tornam esses aspectos evidentes.

Quadro 1 -As fases da Modelagem Matemática e suas características.

\begin{tabular}{|c|c|}
\hline Fase & Principais características \\
\hline Inteiração & $\begin{array}{l}\text { - Inteiração do assunto. } \\
\text { - Consulta a diferentes fontes de pesquisa. } \\
\text { - Conhecimento de aspectos relativos ao tema. } \\
\text {-Coleta, discussão, registro e seleção de informações. } \\
\text { - Formulação ou identificação de um problema a resolver. } \\
\text { - Definição de metas para a resolução do problema. }\end{array}$ \\
\hline Matematização & $\begin{array}{l}\text { - Tradução do problema da linguagem natural para a linguagem matemática. } \\
\text { - Seleção de variáveis. } \\
\text { - Levantamento de hipóteses. } \\
\text { - Evidência de técnicas e procedimentos matemáticos que podem auxiliar na } \\
\text { resolução do problema em estudo. }\end{array}$ \\
\hline Resolução & $\begin{array}{l}\text { - Utilização de conceitos, técnicas, métodos e representações matemáticas. } \\
\text { - Recorrência a ferramentas tecnológicas e/ou computacionais. } \\
\text { - Construção e/ou utilização de modelos matemáticos. } \\
\text {-Respostas às questões e à problemática admitida na situação inicial. }\end{array}$ \\
\hline $\begin{array}{l}\text { Interpretação } \\
\text { de Resultados e } \\
\text { Validação }\end{array}$ & $\begin{array}{l}\text { - Análise do(s) resultado(s) obtido(s). } \\
\text { - Verificação dos métodos e/ou procedimentos matemáticos utilizados, } \\
\text { analisando se foram adequados para responder ao problema em estudo. } \\
\text {-Certificação de que a(s) solução(ões) encontrada(s) satisfaz(em) o problema } \\
\text { identificado. }\end{array}$ \\
\hline
\end{tabular}

Fonte: adaptado de Castro (2017).

Convém destacar que não necessariamente todas essas características vão acontecer em uma mesma atividade, nem mesmo há uma ordem para que elas aconteçam. Contudo, os aspectos supracitados, inerentes a uma atividade de modelagem matemática, são o que, de fato, ficam evidentes no desenvolvimento de uma atividade de modelagem e estão associados às fases da Modelagem Matemática. 
Isso implica reconhecer que tão importante quanto a solução para o problema são os encaminhamentos e procedimentos que medeiam a transição da situação inicial para a situação final.

A resposta para o problema depende, de modo geral, dos encaminhamentos e procedimentos adotados pelos alunos e de seus conhecimentos e das intervenções realizadas pelo professor. Todavia, é importante que tais intervenções e a independência dos alunos mantenham certo grau de equilíbrio, de forma a garantir autonomia dos alunos frente ao problema em estudo e em relação às estratégias de resolução adotadas (VERONEZ, 2013, p.27).

A ação do professor em atividades de modelagem matemática é de mediador entre o conhecimento matemático dos alunos e os encaminhamentos por eles assumidos. Na busca por responder ao problema identificado, decorrente da situação a ser investigada, é que as intervenções docentes acontecem. Porém, elas devem oportunizar a autonomia do aluno na tomada de decisões, na escolha de estratégias e na adoção de procedimentos e encaminhamentos que visam construir soluções para o problema que originou a atividade.

Segundo Vertuan (2010, p.2), atividades de modelagem matemática evidenciam "uma representação da realidade sob a ótica daqueles que investigam a situação. Isso implica no fato de que diferentes grupos de alunos podem construir representações distintas de uma mesma realidade, ou seja, de uma mesma situação". Dessa maneira, cada situação pode ser vista sob diferentes ângulos e admitir inúmeras possibilidades de problemas a serem explorados, o que suscita também diversos resultados, válidos ou não.

Nesse contexto Veronez (2013, p.21), escreve que "se o ponto de partida de uma atividade de modelagem matemática é uma situação, diversas são as possibilidades de investigação a seu respeito". Para esta autora são inúmeras as possibilidades de encaminhamentos que podem ser assumidos para uma mesma situação, já que após realizar "um recorte" de tal situação os problemas evidenciados podem ser distintos, conduzindo diversas formas de investigações.

A partir do propósito desta investigação, que considera dois encaminhamentos dados a um mesmo tema que origina, portanto, duas atividades de modelagem matemática, apresentamos nossas opções metodológicas na seção a seguir.

\section{ASPECTOS METODOLÓGICOS}

Para a presente investigação, que segue orientações da abordagem qualitativa na medida em que se preocupa com a compreensão interpretativa do fenômeno e das experiências do sujeito no contexto em que foram evidenciadas (GOLDENBERG, 2004), consideramos os registros dos sujeitos envolvidos na pesquisa, as anotações e observações feitas pela professora e as transcrições das gravações em áudio dos diálogos desses sujeitos. Todos esses materiais referemse ao desenvolvimento de duas atividades de modelagem matemática, por dois grupos de alunos de turmas distintas.

As atividades de modelagem matemática abordadas neste trabalho foram desenvolvidas, durante 15 aulas, por alunos de duas turmas de 8o ano do Ensino 
Fundamental, denominadas $8^{\circ} \mathrm{A}$ e $8^{\circ} \mathrm{B}$, de uma escola da rede pública de ensino, em uma comunidade rural, em que a primeira autora era também professora da disciplina de Matemática nas turmas referidas. Nessas atividades a escolha do tema ficou a critério dos alunos a partir do convite da professora aos grupos, solicitando que escolhessem um tema de seu interesse ou que apresentassem alguma relação com sua realidade. Assim, cada grupo teve a oportunidade de optar por um assunto de seu interesse, ou seja, cada grupo trabalhou com um tema diferente do outro. Na turma A, por exemplo, os temas escolhidos foram: música, milho, futebol, feijão, dinossauros, planetas do sistema solar e fumicultura. Enquanto que na turma b, os alunos definiram como tema de estudo WhatsApp, maracujá, motos, erva-mate e fumicultura.

Neste estudo, apresentamos algumas reflexões sobre o tema fumicultura, ou seja, cultivo de tabaco/fumo, pelo fato de que ambos os grupos de alunos, um da turma $A$ e outro da turma B, optarem pelo mesmo tema. Essa escolha em comum instigou nosso interesse por discutir acerca dos diferentes encaminhamentos assumidos pelos alunos ao desenvolverem atividades de modelagem matemática distintas, a partir do mesmo tema.

Tendo esse objetivo, organizamos os dados coletados de modo a facilitar a compreensão e argumentação que aqui apresentamos. Essa organização nos auxiliou na análise dos registros dos alunos, das transcrições dos áudios e do recorte dessas transcrições trazidos em forma de Episódios. Tais Episódios retratam os diálogos, do grupo $A$, constituído por três meninos aos quais trataremos como $A 1$, $A 2$ e $A 3$ e do grupo $B$, formadas por três meninas, nominadas B1, B2 e B3. Todos esses alunos têm idade entre 13 e 14 anos.

A pesquisa foi submetida ao Comitê de Ética em Pesquisa (COMEP) da Unicentro, por meio da Plataforma Brasil, que apresenta o CAAE (47576815.5.0000.0106) e cujo parecer de aprovação (número1.213.285) foi gerado em 03 de setembro de 2015.

\section{DIFERENTES ENCAMINHAMENTOS PARA UM MESMO TEMA EM MODELAGEM MATEMÁTICA}

A justificativa para a escolha do tema fumicultura, de ambos os grupos, foi amparado no fato de que os pais, da maioria dos alunos desses grupos, trabalhavam no cultivo de tabaco. Sendo membros de famílias de fumicultores, a maioria das informações coletadas pelos alunos foi obtida com os pais e/ou com representantes de indústria fumageira.

A opção por um tema próximo da realidade dos alunos se aproxima da assertiva de D'Ambrósio (2016, p.2), ao enfatizar que "a ação resulta de estratégias motivadas pela necessidade e/ou desejo que tem cada indivíduo de explicar, conhecer, entender, lidar, manejar, conviver com a realidade, e obviamente resulta da informação que o indivíduo dela recebeu". Fato que também se evidencia nesses relatos dos alunos: "nós achamos que fosse ser fácil", "porque sei sobre o tema" e "porque tem muita matemática".

No grupo A, partindo da situação inicial "processos de produção de fardos de fumo", a fase inteiração consistiu em obter informações a partir de entrevistas com familiares, de pesquisa de campo. Os dados coletados se relacionaram a 
conhecimentos diversos como: importância econômica da fumicultura para a região, perigo dos agrotóxicos, uso dos Equipamentos de Proteção Individual (EPI's), malefícios do tabaco, processo de produção, entre outros. A partir disso, os alunos selecionaram as informações relacionadas ao tamanho da folha, quantidade de folhas por boneca ${ }^{3}$, quantidade de bonecas em um fardo, quantidade de cabinhos que cabem em uma estufa, entre outras de conhecimento cotidiano.

O Quadro 2 ilustra algumas dessas informações.

Quadro 2 - Informações sobre produção de fumo.

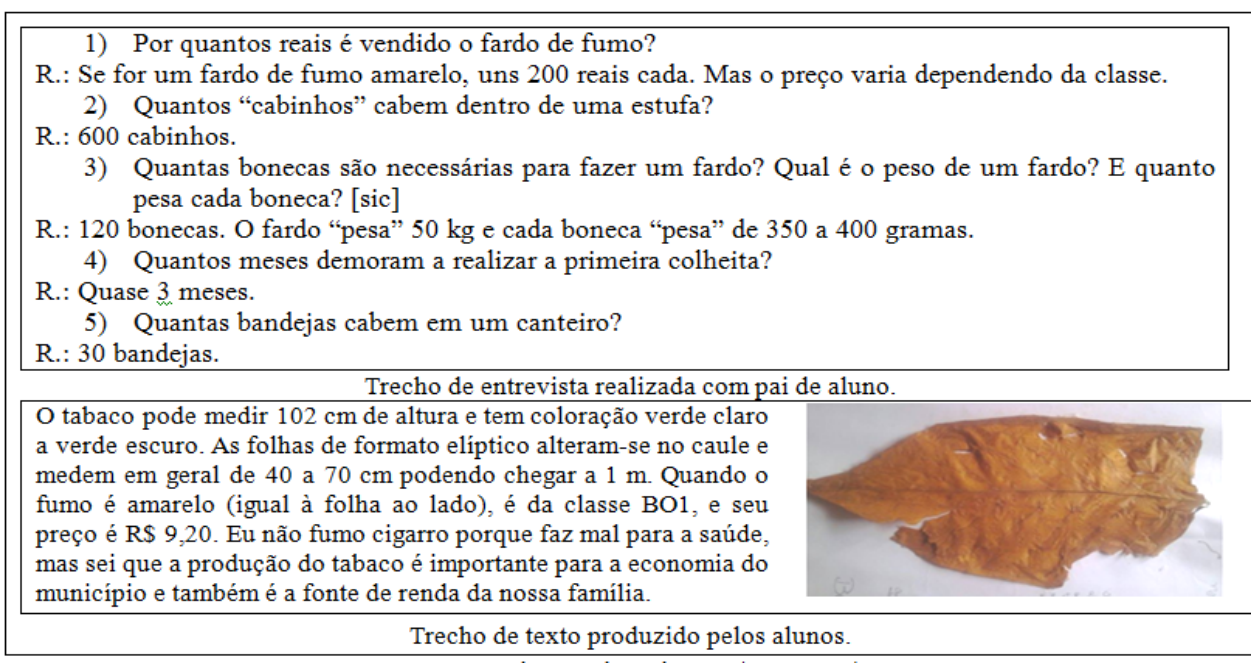

Fonte: registros dos alunos - Grupo A (2015).

Ao analisar os elementos obtidos na pesquisa que realizaram, ainda na fase inteiração, o grupo foi encaminhando a estruturação do problema. Essa estruturação iniciou-se com discussões acerca das informações obtidas e da afirmação levantada por um dos alunos, quando disse que, quanto maior for o tamanho (comprimento) das folhas, menos bonecas serão necessárias para encher a enfardadeira. Ele completou ainda que a quantidade de 120 bonecas que são necessárias para fazer um fardo (conforme registro no quadro 2) pode variar. Diante disso, o grupo discutiu que, embora a quantidade de bonecas varie, o tamanho do fardo é sempre igual, pois se utiliza a enfardadeira para, nas palavras deles, "apertar" o fumo e amarrá-lo em fardos. Esse termo "apertar" foi discutido com a professora e demais colegas, passando a substituir seu uso por pressionar ou prensar. Outro aluno desse grupo ressaltou que, ao prensar o fumo na enfardadeira, ele diminui de tamanho, ou seja, como há esse processo de prensar as bonecas, independentemente da quantidade inicial elas perdem "tamanho" e os fardos ficam sempre muito parecidos (em dimensões). A questão do "tamanho" dos fardos, tornou-se também motivo de discussão e estudo, que após várias indicações, questionamentos e esclarecimentos da professora, compreenderam se tratar do volume. Assim, eles encaminharam o seguinte problema: "Qual o volume que as bonecas de fumo diminuem ao serem prensadas na enfardadeira?"

Enunciado esse problema, os alunos passaram às fases matematização $e$ resolução, que os levou a considerar as dimensões da enfardadeira utilizada pelos familiares de um dos alunos do grupo como hipótese, reconhecendo que podem existir outros tamanhos. Também definem as variáveis e dados considerados para 
o desenvolvimento da atividade, com ênfase nas dimensões de uma caixa enfardadeira. Sendo assim, os alunos identificaram as medidas da "caixa de enfardar", a qual é utilizada para prensar o fumo formando fardos. Essa medida foi obtida pelos alunos, quando eles fizeram a medição da enfardadeira que um deles tinha em casa. A partir disso, eles conheciam a medida do comprimento e da altura, $60 \mathrm{~cm}$ e $1 \mathrm{~m}$, respectivamente, porém, para calcular o volume eles ainda precisavam da medida do comprimento da enfardadeira. O Episódio A1 retrata a dificuldade em chegar a um consenso, vivenciada pelos alunos.

\section{Episódio A1}

\section{A1: $E$ $45 \mathrm{~cm}$.}

\section{A2: Da onde? Não é essa medida![sic]}

Professora: Vamos pegar duas réguas para ver. Olhem, $45 \mathrm{~cm}$ é mais ou menos desse tamanho aqui.

\section{A2: Está vendo. Falei que é maior.}

\section{A1: A nossa enfardadeira é desse tamanho! Vamos usar essa medida?}

Após chegar ao consenso de usar as medidas apresentadas por A1, os alunos esboçaram o desenho da enfardadeira conforme Figura 1.

Figura 1 - Desenho do formato da enfardadeira de fumo

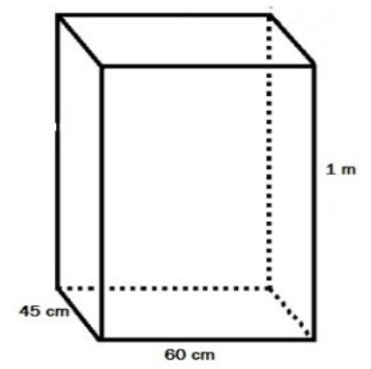

Com essa representação os alunos assumiram as dimensões da caixa como sendo $1 \mathrm{~m}$ de altura, $60 \mathrm{~cm}$ de comprimento e $45 \mathrm{~cm}$ de largura e passaram a buscar maneiras sobre como realizar o cálculo do volume. Depois de debaterem acerca de alguns questionamentos e de uma breve explicação da professora, os alunos conseguiram compreender o conceito de $\mathrm{m}^{3} \mathrm{e}$, a partir de então, construírem a ideia de volume. Ou seja, compreenderam o que significa o volume enquanto grandeza ao calcular o volume de um paralelepípedo retângulo a partir da expressão: $v=c . l . a$, em que $v$ é volume; $c$ comprimento; / largura e; $a$ altura.

Porém, eles estavam trabalhando com unidades diferentes ( $\mathrm{cm} \mathrm{e} \mathrm{m}$ ) e deveriam fazer a transformação de unidade de medidas para, posteriormente, realizar o cálculo de volume. Para realizar a transformação de unidades $(\mathrm{cm}$ para $\mathrm{m}$ ) os alunos se utilizaram de regra de três simples após reconhecer que $1 \mathrm{~m}$ é constituído de $100 \mathrm{~cm}$. Os resultados expressos no Quadro 3 ilustram o cálculo do volume realizado pelos alunos.

Quadro 3 - Cálculo do volume da enfardadeira cheia de bonecas de fumo.

\begin{tabular}{|c|c|}
\hline $\begin{aligned} \mathrm{Em} \mathrm{cm}^{3}: \mathrm{V} & =c \cdot I . a \\
\mathrm{~V} & =60.45 .100 \\
\mathrm{~V} & =270.000 \mathrm{~cm}^{3}\end{aligned}$ & $\begin{aligned} \mathrm{Em} \mathrm{m}^{3}: \mathrm{V} & =c \cdot I \cdot a \\
\mathrm{~V} & =0,6 \cdot 0,45 \cdot 1 \\
\mathrm{~V} & =0,27 \mathrm{~m}^{3}\end{aligned}$ \\
\hline
\end{tabular}

Fonte: registros dos alunos - Grupo A (2015). 
Ao conhecer o volume da caixa de enfardar, os alunos calcularam o volume do fardo de fumo prensado (Quadro 4), para isso, a professora questionou-os sobre quantos $\mathrm{cm}$ consegue-se prensar o fumo, ou seja, quanto diminui ou "abaixa" o fardo ao ser prensado. Os alunos relataram que diminui em média $50 \mathrm{~cm}$, ou seja, mas que às vezes pode diminuir um pouco menos. Portanto, o fardo do fumo teria dimensões iguais a $50 \mathrm{~cm}$ de altura, $60 \mathrm{~cm}$ de comprimento e $45 \mathrm{~cm}$ de largura, visto que, pelas colocações dos alunos, as medidas de comprimento e de largura não sofrem alteração.

Quadro 4 - Cálculo do volume das bonecas de fumo prensadas.

\begin{tabular}{|c|c|}
\hline $\begin{aligned} \mathrm{Em} \mathrm{cm}^{3}: \mathrm{V} & =\mathrm{c} . \mathrm{I} \cdot \mathrm{a} \\
\mathrm{V} & =60.45 .50 \\
\mathrm{~V} & =135.000 \mathrm{~cm}^{3}\end{aligned}$ & $\begin{aligned} \mathrm{Em} \mathrm{m}^{3}: \mathrm{V} & =\mathrm{c} \cdot \mathrm{I} \cdot \mathrm{a} \\
\mathrm{V} & =0,6 \cdot 0,45 \cdot 0,5 \\
\mathrm{~V} & =0,135 \mathrm{~m}^{3}\end{aligned}$ \\
\hline
\end{tabular}

Fonte: registro dos alunos.

Um fato interessante nesse momento da atividade de modelagem foi que os alunos perceberam que uma das medidas sendo reduzida à metade, teria o volume das bonecas também diminuído à metade, confirmando isso, inclusive pelo cálculo em porcentagem. Quando eles relataram que essa redução nem sempre acontece nessa proporção, porque ao passar pelo processo de compressão para fabricação de fardos de fumo, o volume das bonecas de fumo classificado e seco, depende da classe de fumo enfardada, fizeram novos cálculos para quando as bonecas prensadas diminuem menos (45, 40 e 38). O que os permitiu concluir que o fardo pode diminuir entre $40 \%$ a $50 \%$, dependendo da classe de fumo enfardada. No primeiro caso estudado, o volume diminuiu de $0,27 \mathrm{~m}^{3}$ para $0,135 \mathrm{~m}^{3}$, ou seja, a metade, porque foi considerado uma diminuição de $50 \%$ no processo de compressão. Assim, escreveram as seguintes fórmulas $V_{t}=$ c. I. $a-50 \%$ (c. I. a) e $V_{t}=$ $\frac{c . l . a}{2}$, isto é, o volume total $\left(V_{t}\right)$ pode ser calculado, ao invés de passo a passo como eles fizeram inicialmente, por meio de uma única forma: a diferença entre o volume total (c.l.a) do volume prensado (" $x$ "\% .c.l.a) o que depende da medida que a altura das bonecas reduz.

Na fase interpretação e validação de resultados os alunos passaram a conferir as medidas reais da enfardadeira e do fardo de fumo pronto, bem como a verificar se os cálculos realizados estavam corretos, para então validar os resultados, com vista à possível aceitação dos resultados obtidos.

Os alunos elaboraram um cartaz com informações que consideraram relevantes e construíram uma réplica da enfardadeira, utilizando papelão e tinta, como elemento auxiliar visual para facilitar o entendimento do trabalho e expor a situação final, que se apresentava como o cálculo do volume de uma enfardadeira cheia de bonecas de fumo e volume do fardo já com as bonecas de fumo prensadas.

Ao comunicar os resultados os alunos focalizaram as dimensões utilizadas para descrever o tamanho da enfardadeira, porém as medidas utilizadas pelo Grupo A foram contestadas por um aluno (A4) de outro grupo, que também tinha conhecimento sobre o tema em estudo, conforme diálogo apresentado no Episódio A2. 


\section{Episódio A2}

A4: Mas desse tamanho é muito pequena. A nossa é maior.

A1: Mas a nossa é desse tamanho mesmo.

\section{A2: Eu também achava que era maior.}

A5: Mas é que existem tamanhos diferentes gente! Depende de onde compra ou encomenda para fazer sob medida. Nós temos da grande e da pequena. [sic]

O aluno A5 que, assim como A4, pertencia a outro grupo, apresentou a possibilidade de existirem caixas de enfardar de diferentes tamanhos, o que levou os alunos a concluir que os cálculos realizados estavam corretos para a situação específica colocada por A1. Sendo assim, finalizaram a argumentação da validade dos resultados e deram a atividade por concluída.

Por sua vez, o grupo B partiu da situação inicial "Produção das colheitas baixeira e ponteira do fumo" e, na fase inteiração, realizaram a coleta dos dados por meio de entrevista com familiares, entrevista com funcionário de indústria tabageira (chamado por eles de "instrutor de fumo"), análise de notas de produtor rural e pesquisa em sites relacionados. As informações obtidas atendiam a conhecimentos diversos tais como: produção, consumo e estoque de fumo ao longo dos anos, exportação e consumo mundial de fumo, trabalho infantil na produção de fumo, vantagens do cultivo de fumo em relação a outras culturas, histórico da introdução da fumicultura na região e as etapas de cultivo. No Quadro 5 aparecem algumas das informações coletadas pelos alunos.

Quadro 5 - Informações sobre produção de fumo.

O fumo na nossa região

A produção do fumo passou a ganhar espaço a partir de 1492. Um dos primeiros produtores e incentivador dessa cultura foi Cristoball Collon, no país de Cuba. Na nossa região o fumo é uma das principais fontes de renda e embora nem todos os anos a produção seja boa e nem sempre o lucro seja certo, os agricultores da nossa comunidade continuam a cultivá-lo. Isso porque, os agricultores daqui têm pouco recurso e pequenas propriedades de terra, além disso, não exige muitos equipamentos modernos. Sendo assim, o Fumo acaba se tornando a melhor coisa a ser cultivada nessa região. Trecho do texto produzido pelos alunos.

1) Quantas bandejas são colocadas em cada túnel? Quantas mudas são produzidas em cada bandeja?

R.: 60 bandejas de 200 mudas cada.

2) Quanto tempo leva para secar uma "estufada" de fumo? [sic]

R.: Depende do tamanho (capacidade) da estufa, uma pequena geralmente demora 6 noites, já a grande de 8 a 9 noites.

3) Quanto tempo demora para realizar a primeira colheita do fumo? [sic]

R.: Em média 70 dias, caso esteja maduro.

4) Quantos túneis devemos fazer para plantar 90 mil pés de fumo? [sic]

R.: 9 canteiros de 12 mil mudas, porque sempre é preciso repor alguma muda que estraga, não nasce ou replantar as que não vingam.

5) Quantos metros de lenha são utilizados para secar uma estufa cheia de fumo?

R.: De 4 a 5 metros.

6) Quantas mudas e quantos arcos cabem em um canteiro?

R.: Um total de 12 mil mudas. Cabem 11 arcos. Trecho da entrevista com um pai de aluno.

Fonte: Registro dos alunos - Grupo B (2015).

A definição de um problema a resolver causou muitas divergências e indecisão. Por ser um tema muito amplo, as alunas tiveram dificuldade em delimitar um problema para ser explorado, conforme aparece no Episódio B1. 


\section{Episódio B1}

Professora: Olha, pensem que vocês podem escolher algum aspecto que vocês conhecem em parte e que gostariam de aprender mais sobre ele.

B1: Eu queria pesquisar sobre preço ou a quantidade produzida em cada colheita.

B2: Pois é, mas a gente sabe os preços das classes.

B3: Eu não entendo muito.

B2: E se nós estudássemos sobre o lucro de cada colheita?

B1: Baixeiro dá menos e ponteira dá melhor!

Professora: Primeira e última colheita é isso?

B2: Sim. Vamos pesquisar a diferença entre elas?

Ainda na fase inteiração, depois de muito diálogo e com o auxílio da professora, as alunas optam por estudar o seguinte problema: "Em uma colheita, qual é a produção estimada de fumo (considerando ele seco, sua classe e a produção em Kg)? Qual a diferença de produção do baixeiro e da ponteira?"

Após a definição do problema, as alunas passaram às fases matematização $e$ resolução. Nas referidas fases, primeiramente, começaram por identificar os dados a serem considerados e as variáveis que precisariam definir para ajudar a resolver o problema, sendo elas: quantidade de fumo cultivada durante um período/ano (90 mil pés, médio porte), produção de fumo seco na primeira colheita da safra (baixeira), produção de fumo seco na última colheita da mesma safra (ponteira), classificação das folhas de fumo seco, preço pago ao agricultor por kg e por classe de fumo seco ${ }^{4}$. Uma das alunas, B1, ficou encarregada de levantar informações complementares com seus pais, enquanto B2 falaria com uma pessoa de seu conhecimento que trabalha como instrutor em uma indústria de fumo.

Com base em algumas informações, as alunas simularam situações (conforme estabelecida na identificação de dados e variáveis) que Ihes permitiram elaborar os Quadros6 e 7que, juntamente com as observações e argumentações finais, tende a responder ao problema evidenciado no início da atividade de modelagem.

Quadro 6 - Estufada de fumo de ponteira (90 mil pés).

\begin{tabular}{|c|c|c|c|c|}
\hline Classe & $\begin{array}{c}\text { Preço Médio } \\
\text { por Kg (R\$) }\end{array}$ & $\begin{array}{c}\text { Quantidade } \\
\text { de Fardos }\end{array}$ & $\begin{array}{c}\text { Peso dos } \\
\text { fardos } \\
\text { (Kg) }\end{array}$ & $\begin{array}{c}\text { Total } \\
\text { (R\$) }\end{array}$ \\
\hline BO1 & 9,70 & 6 & 300 & 2.910 \\
\hline BO2 & 8,43 & 4 & 180 & $1,517,40$ \\
\hline CO3 & 7,12 & 3 & 129 & 918,48 \\
\hline---- & ---- & 13 & 509 & $5.345,88$ \\
\hline
\end{tabular}

Fonte: registros dos alunos (2015).

Quadro 7 - Estufada de fumo de baixeiro (90 mil pés).

\begin{tabular}{|c|c|c|c|c|}
\hline Classe & $\begin{array}{c}\text { Preço Médio } \\
\text { por Kg (R\$) }\end{array}$ & $\begin{array}{c}\text { Quantidade } \\
\text { de Fardos }\end{array}$ & $\begin{array}{c}\text { Peso dos } \\
\text { fardos } \\
(\mathrm{Kg})\end{array}$ & $\begin{array}{c}\text { Total } \\
\text { (R\$) }\end{array}$ \\
\hline CO2 & 6,50 & 5 & 210 & 1.365 \\
\hline KL & 3,42 & 2 & 80 & 273,60 \\
\hline
\end{tabular}




\begin{tabular}{|c|c|c|c|c|}
\hline $\mathbf{M N}$ & 3,40 & 1 & 39 & 132,60 \\
\hline KM & 2,63 & 2 & 74 & 194,62 \\
\hline & & 10 & 403 & $1.965,82$ \\
\hline
\end{tabular}

Fonte: registros dos alunos (2015).

Olhando para as duas fases de colheitas, as alunas realizaram outros cálculos que permitiram inferir que a diferença entre as duas fases foi de 3 fardos, $106 \mathrm{~kg}$ e $R \$ 3.380,06$. Isso significa que a produção de fumo baixeiro corresponde, em média, a aproximadamente $36,77 \%$ do valor total pago pela produção de fumo ponteira.

Apesar de aceita a resposta, as alunas enfatizaram alguns pontos importantes a serem considerados acerca do resultado. Tais considerações podem ser observadas no Quadro 8.

Quadro 8 - Restrições à solução construída.

- Os resultados obtidos são válidos para determinada safra. Os resultados não valem para todos os anos.

- Os preços variam todos os anos, ou seja, a valorização pode ser maior em um ano e menor em outro. Isso depende da Companhia e do mercado do tabaco.

- A produção depende de vários fatores como: condições de tempo, preparo da terra, forma de secar, entre outros.

- Nem tudo é lucro. Parte é para pagar os gastos com a produção (insumos, agrotóxicos, mão de obra, luz, etc.).

Fonte: diálogo dos alunos (2015).

Com o intuito de verificar a validade dos resultados encontrados, as alunas confrontaram suas respostas com notas de produtor rural e certificaram as soluções com fumicultores, para então, o resultado ser interpretado e validado. Essa fase da atividade de modelagem matemática pode ser descrita como interpretação e validação de resultados. Após aceitar a resposta como válida e próxima do que acontece na realidade e realizar as observações necessárias, as alunas realizaram argumentação e comunicação dos resultados aos demais colegas de classe.

\section{ALGUMAS CONSIDERAÇÕES}

Nesse estudo, a escolha do tema fumicultura, a qual os alunos tinham familiaridade e entendiam ser mais fácil buscar informações, além de permitir compreender e descrever situações reais utilizando conhecimentos matemáticos, viabilizou o desenvolvimento de duas atividades de modelagem matemática com o mesmo tema: fumicultura.

Daí a proximidade do estudo realizado com o que Barbosa (2001) expõe quando afirma que "conceitos e ideias matemáticas exploradas dependem do encaminhamento que só se sabe à medida que os alunos desenvolvem a atividade" (p.5). Também se aproxima da ideia de que se a Modelagem Matemática pode ser entendida como uma oportunidade para os alunos indagarem situações da realidade ou de seu interesse por meio da matemática, sem procedimentos préestabelecidos, havendo possibilidades diversas de encaminhamentos para isso. 
Porém, no ambiente de modelagem matemática em que se vise possibilitar aos alunos a escolha de um tema de seu interesse e/ou de sua realidade e criar possibilidades para que realizem suas investigações, é a ação do professor que favorece diferentes olhares para um mesmo tema. É a dinâmica instaurada na aula que possibilita que os alunos, mesmo escolhendo um mesmo tema, conduzam diferentes encaminhamentos e assumam diferentes procedimentos, dependendo do interesse de cada grupo.

O estudo do tema "fumicultura" contribuiu para a aprendizagem de conceitos matemáticos ao mesmo tempo em que situações de sua realidade eram discutidas e analisadas, já que os alunos tinham interesse em investigar sobre tal tema. Sendo a fumicultura um tema amplo, o problema a ser definido poderia tomar diferentes rumos, e foi o que de fato aconteceu. A característica de uma atividade de modelagem ser aberta e permitir diferentes olhares para determinado tema se ratifica neste estudo e sugere inclusive como isso pode acontecer em um contexto de sala de aula. Embora as atividades de modelagem abordadas sejam distintas, inferimos que há algumas semelhanças na forma como os alunos conduziram tais atividades. Na fase inteiração, por exemplo, a busca por informações se deu, em ambos os grupos, por meio de entrevistas com pessoas que trabalhavam na produção do fumo. Além disso, existem aspectos semelhantes nas perguntas elaboradas pelos alunos como a quantidade de bandejas que cabem em um túnel/canteiro. Talvez o que fez com as atividades de modelagem tomassem rumos diferentes tenham sido as respostas obtidas pelos alunos, já que elas diferem de um grupo para outro. Daí o entendimento de que os dados coletados são determinantes para a definição de um problema a resolver, principalmente se este não for evidenciado antes de tal coleta e, de que a base de referência da coleta de dados pode sugerir caminhos distintos para a atividade de modelagem matemática.

Essas atividades revelam diferenças e semelhanças na definição do problema e no direcionamento da sua resolução pelos alunos. Assim, os conceitos matemáticos requeridos para resolver o problema de cada uma das atividades de modelagem são diferentes e exigem dos alunos também competências distintas, mesmo que em ambas as atividades os conceitos utilizados sejam de conhecimento de alunos de $8^{\circ}$ ano do Ensino Fundamental. Ou seja, na matematização e resolução, enquanto o Grupo A utiliza conhecimentos de geometria, por meio do cálculo de volume e transformação de unidades, o Grupo B fez uso de conhecimentos de operações com números racionais, média aritmética e porcentagem.

Também cabe destacar que os encaminhamentos assumidos pelos alunos na fase interpretação de resultados e validação novamente são diferentes. Enquanto o Grupo A busca discutir e validar os resultados por eles obtidos entre os alunos do grupo e com os colegas de turma, os alunos do grupo B validaram suas soluções conferindo-as com informações contidas em documentos e com os pais para, a partir de então, apresentar os resultados à turma.

Outra constatação importante obtida a partir da análise das atividades é sobre o modelo, o qual, de fato, denotou uma representação simplificada que os alunos construíram sobre descrever fenômenos da realidade. Isso vem ao encontro do que Barbosa (2009) afirma ao escrever que o modelo é um "retrato aproximado da realidade". Tal como retrato, ele apresenta apenas uma parte específica da 
realidade, que é muito mais ampla. Por exemplo, na atividade do grupo $A$, o modelo obtido retrata uma percepção capaz de responder àquela questão em particular.

Em ambas as atividades notamos algumas restrições quanto às respostas obtidas. Isso porque os grupos ao buscar certificarem-se da validade dos resultados destacam que, embora para a circunstância em particular que estavam estudando eles eram verdadeiros; não representam uma verdade fixa para outros casos similares. No grupo A, por exemplo, foi explicitada a existência de enfardadeira com dimensões de tamanhos diversos, enquanto que no grupo B, as alunas salientaram o fato de que os dados envolvidos (como preço, peso, classe de fumo) eram variáveis que dependiam de diversos fatores (econômicos, ambientais, sociais). Isso evidencia o potencial que atividades de modelagem matemática apresentam para desencadear o senso crítico do aluno, desenvolvendo capacidade de argumentar respostas ao passo que confronta seus conhecimentos matemáticos com conhecimentos relativos à situação em foco, de apresentar justificativas e de refletir sobre elementos matemáticos presentes em situações da realidade.

Em suma, atividades de modelagem matemática desenvolvidas a partir de uma mesma temática podem viabilizar estudo de conceitos matemáticos distintos e proporcionar olhares abrangentes, já que problemas diferentes conduzem a compreensões amplas do tema em estudo e podem suscitar o estudo de diversos conceitos matemáticos, necessários à sua resolução. Ainda, os encaminhamentos assumidos pelos alunos em atividades de modelagem dependem de diversos fatores, entre eles: a criticidade e/ou a necessidade do aluno, a mediação do professor e o trabalho em grupo. Esses fatores podem se configurar como fonte de análise em estudos futuros. 


\title{
Mathematical modeling: different orientations for same theme
}

\begin{abstract}
Research about mathematical modelling have presented relevant contributions to mathematics teaching. In addition, those researches have motivated reflections about resource as a teaching method aimed at understanding situations or students' interest situations. In this paper, we are analyzing the way that two students groups from eighth grade of Elementary School developed a modelling activity which theme is tobacco farming. Both groups chose this theme because they live in a region where tobacco farming in very common. Our intention is to discuss about different ways to develop a mathematical modelling activity with the same theme. This way, we present how both students groups developed the activity, highlighting the modelling activity dynamics in the classroom. To do this, we have followed qualitative research principles; to use data that is data interpretation, we have observed the developed activity in classroom, we have done audio recording and transcriptions, and we have used students' written productions. Although the results indicate that in a modelling activity the same theme can be developed in a similar way, other aspects. In environment of mathematical modeling the application of the common theme varies, for example, mathematics concepts used in the activity can be different.
\end{abstract}

KEYWORDS: Mathematical modeling activities. Phases of the Mathematical Modeling. Orientations. 


\section{AGRADECIMENTOS}

1- Modelo matemático, nesse caso, "é o que 'dá forma' à solução do problema" (ALMEIDA; SILVA; VERTUAN, 2013, p. 15). Nessa compreensão o modelo matemático se apresenta por meio de uma estrutura matemática, podendo ser uma tabela, um gráfico, uma expressão, uma equação, uma função.

2- Neste trabalho, não é nosso foco mostrar a não linearidade entre as fases.

3- Conjunto de aproximadamente 10 folhas amarrada, depois de secas.

4- $O$ tipo de tabaco exige características de cultivo e cura bem particulares, para que se alcance a melhor qualidade possível nas folhas, definida a partir de características como cor, medida de massa, espessura da folha. Essa qualidade, exigida e definida pelas indústrias fumageiras, é que determina o valor pago pelo fumo produzido no campo. O valor determinado para cada classe, varia de acordo com o desempenho do mercado (lei de oferta e procura) o que influencia na estipulação dos preços por Comissões Técnicas de representação dos produtores e das empresas.

\section{REFERÊNCIAS}

ALMEIDA, L. W.; SILVA, K. P.; VERTUAN, R. E. Modelagem Matemática na Educação Básica. 1.ed. 1a reimpressão. SP: Contexto, 2013.

BARBOSA, J. C. Modelagem na Educação Matemática: contribuições para o debate teórico. In: Reunião Anual da ANPED, 24, Caxambu. Anais. RJ: ANPED, 2001. 1 CD-ROM.

BARBOSA, J. C. Modelagem e Modelos Matemáticos na Educação Científica. ALEXANDRIA Revista de Educação em Ciência e Tecnologia, v.2, n2, p.69-85, jul., 2009.

CASTRO, E. M. V. C. Atividades de modelagem matemática desenvolvidas por alunos de 8 ano de Ensino Fundamental de escola do campo. Produto Educacional. Programa de Pós Graduação em Ensino de Ciências Naturais e Matemática, Unicentro, PR. 2017.

D'AMBROSIO, U. Dos fatos reais à Modelagem - Uma proposta de conhecimento matemático. Disponível em: http://vello.sites.uol.com.br/modelos.htm. Acesso em: 02/02/2016.

GOLDENBERG, M.A arte de pesquisar: como fazer pesquisa qualitativa em pesquisas sociais. Editora Record, 8ªedição. Rio de Janeiro/São Paulo, 2004. 
TORTOLA, E.; REZENDE, V.; SANTOS, T.S. Modelagem Matemática: Contribuições Para o Ensino e Aprendizagem da Matemática. Anais do X Encontro Nacional de Educação Matemática Relato de Experiência. X Encontro Nacional de Educação Matemática Educação Matemática, Cultura e Diversidade Salvador - BA, 7 a 9 de Julho de 2010.

VERONEZ, M. R. D. As funções dos signos em atividades de modelagem matemática. 2013. 176p. Tese de Doutorado (Pós-Graduação em Ensino de Ciências e Educação Matemática) - Universidade Estadual de Londrina, Londrina, 2013.

VERONEZ, M. R. D.; VELEDA, G.G. Reflexões sobre a Realidade em uma Atividade de Modelagem Matemática. Revista do Programa de Pós-Graduação Em Educação Matemática da Universidade Federal de Mato Grosso Do Sul (UFMS) V 9, n 21, 2016.

VERTUAN, R.E. Modelagem Matemática Na Educação Básica. Modelagem Matemática: perspectivas interdisciplinares para o ensino e a aprendizagem de matemática. IV EPMEM - Encontro Paranaense De Modelagem Em Educação Matemática. Maringá - PR, 11 a 13 de Novembro de 2010.

Recebido: 15 fev. 2018

Aprovado: 01 jul. 2018

DOI: $10.3895 /$ actio.v3n3.7782

Como citar:

CASTRO, E. M. V. de; VERONEZ, M. R. D. Diferentes encaminhamentos para um mesmo tema em

atividades de modelagem matemática. ACTIO, Curitiba, v. 3, n. 3, p. 471-488, set./dez. 2018. Disponível em:

$<$ https://periodicos.utfpr.edu.br/actio>. Acesso em: XXX

Correspondência:

Elida Maiara Velozo de Castro

Rua Ipiranga, 39, Centro, União da Vitória, Paraná, Brasil.

Direito autoral: Este artigo está licenciado sob os termos da Licença Creative Commons-Atribuição 4.0

Internacional.

(c) (i) 